\title{
The influence of soil fertilization on the quality and extraction efficiency of rosemary essential oil (Rosmarinus officinalis L.)
}

\author{
GABRIELA POPESCU ${ }^{1}$, TIBERIU IANCU ${ }^{1}$, COSMIN ALIN POPESCU ${ }^{1}$, SORIN MIHAI \\ STANCIU ${ }^{1}$, ROXANA LUCA ${ }^{1}$, FLORINEL IMBREA ${ }^{\mathbf{1}}$, ISIDORA RADULOV ${ }^{\mathbf{1}}$, FLORIN SALA ${ }^{\mathbf{1}}$, \\ MARIA MIHAELA MOATĂR ${ }^{1 *}$, DORIN DUMITRU CAMEN ${ }^{1 *}$
}

\author{
${ }^{1}$ Banat's University of Agricultural Sciences and Veterinary Medicine „King Michael I of \\ Romania" from Timișoara, Calea Aradului no. 119, 300645, Timisoara, Romania
}

\begin{abstract}
In this study we have investigated the physiological and biochemical behavior of rosemary crop when exposed differentiated fertilizations. The rosemary plants were grown in vegetation pots in the presence of various combinations of the Hoagland nutrient solution including the control group (Vo - Hoagland), group 1 - Hoagland with addition of K X 2 and group 2 - Hoagland with addition of P X 2. During the experimental period we have measured the intensity of photosynthesis by using the gas exchange method and the quantitative determination of chlorophyll pigments. Additionally, we have also extracted and analyzed the volatile compounds. The main compounds identified by gas chromatography and mass spectrophotometry were the monoterpenoids and also lower levels of sesquiterpenoids. Our results show that potassium $(\mathrm{K})$ fertilization had a positive influence on both the amount of dry matter and photosynthesis. Regarding the biochemical analysis of the volatile oils, in group V1, over 16 compounds were identified, with terpinen and cymen, being the most dominant.
\end{abstract}

Keywords Fertilization, bioactive compounds, chlorophyll content, photosynthetic intensity.

To cite this article: POPESCU G, IANCU T, POPESCU CI, MIHAI STANCIU S, LUCA R, IMBREA F, RADULOV I, SALA F, MOATĂR MM, DORIN DUMITRU CAMEN DD. The influence of soil fertilization on the quality and extraction efficiency of rosemary essential oil (Rosmarinus officinalis L.). Rom Biotechnol Lett. 2020; 25(5): 1961-1968. DOI: $10.25083 / \mathrm{rbl} / 25.5 / 1961.1968$

*Corresponding author: DORIN DUMITRU CAMEN, MARIA MIHAELA MOATĂR, Banat's University of Agricultural Sciences and Veterinary Medicine „King Michael I of Romania” from Timișoara, Calea Aradului no. 119, 300645, Timisoara, Romania E-mail: camendorin@yahoo.com mihaelamoatar@yahoo.com 


\section{Introduction}

Rosemary (Rosmarinus officinalis Linn.) is a common houseplant, cultivated in many parts of the world. It is used for flavoring food, beverages, and for certain cosmetics. In folk medicine, it is used as an antispasmodic in renal colic and dysmenorrhea, in relieving respiratory disorders and stimulating hair growth. The rosemary extract relaxes the smooth muscles of the trachea and intestine, and has a choleretic, hepatoprotective and anti-tumorigenic effect. The most important components of rosemary are caffeic acid and its derivatives, such as rosmarinic acid, compounds with antioxidant effect. The rosmarinic acid is well absorbed from the gastrointestinal tract and through the skin. It influences the increase of prostaglandin E2 production and reduces the production of B4 leukotrienes from human polymorphonuclear leukocytes, and inhibits the complement system.

Rosemary acid derivatives and its constituent elements, especially caffeic acid, have a therapeutic potential in the treatment or prevention of asthma, spasmogenic disorders, peptic ulcer, inflammatory diseases, hepatotoxicity, ischemic heart disease, cataracts, cancer and sperm motility (AL-SEREITIA M.R., ABU-AMERB K.M., SENA P., 1999 [1]; KOSAKA and YOKOI, 2003 [2]; Petersen and Simmonds, 2003[3]; BOZIN et al, 2007[4]). Various nutrition preparations and diets have been made based on rosemary in various treatments (BOTSOGLOU et al, 2007 [5]; MOÑINO et al, 2008 [6]; NIETO et al, 2010 [7]).

Due to the importance of the active principles contained in rosemary, (WELLWOOD and COLE, 2004 [8]) developed methods to identify and select accessions of rosemary, Rosmarinus officinalis (L.), producing optimum antioxidant activity.

NABAVI et al, 2015 [9] considers that rosmarinic acid is one of the most important and well known natural antioxidant compounds, which possesses neuroprotective effects in different models of neuroinflammation, neurodegeneration, as well as chemicalinduced neurotoxicity and oxidative stress. Given the above postive effects of the rosemary extracts the enzymatic control of the rosmarinic acid biosynthesis has been previously studied (PETERSEN et al, 2009 [10]).

Some studies have highlighted the influence of vegetation and nutrition factors on the content of active ingredients (PEÑUELAS and LLUSIÀ, 1997 [11]), and others have studied the seasonal variation of rosemary active compounds (LUIS and JOHNSON, 2005 [12]). HIDALGO et al, 1998, [13] observed an excellent correlation $(r=0.93)$ between the carnosic acid concentration and photoperiod in Rosmarinus officinalis. The results presented can be used to improve the selection of raw materials for the extraction of carnosic acid from rosemary.

Given the importance of rosemary through bioactive compounds and the essential oils it contains, the present study looked at how differentiated fertilization with $\mathrm{P}$ and $\mathrm{K}$-added nutrient solutions influences the main physiological processes as well as the quantitative and qualitative analysis of rosemary volatile oil.

The oil is extracted by steam distillation from leaves and flowers. The oil can be used to treat pain from arthritis, asthma, bronchitis, mental fatigue, memory loss and muscle pain. It can be beneficial for skin conditions, dandruff, candida and supports the proper functioning of the immune system and is also a carminative. The main constituents of the oil are $\alpha$-pinene and $\beta$-pinene, camphene, camphor, sabinene, limonene, beta-caryophyllene), phenolic acids (caffeic, gentisic, vanillic, syringic), caffeic acid derivatives (rosmarinic acid), diterpenes (rosmanol, carnosol, carnosic acid), triterpenes (alpha-amirenol and beta-amirenol, ursolic acid, oleanolic acid), flavonoids (diosmin, diosmetin, hesperidin), tannins, waxes, etc. Rosemary oil and its main constituents, ether 1 and cineole8 , act as a good remedy against exhaustion.

Another common name for rosemary is garden rosemary. The parts used are the leaves and flowers, and the medicinal properties: stimulant, antispasmodic, emenagogue, astringent, diaphoretic, carminative, nervine and aromatic, cephalic.

Rosemary is a plant of Mediterranean origin, and the limiting ecological factor is temperature, rosemary requiring a mild climate, without large temperature variations and nottolerating wintering except in particularly favorable conditions, without temperatures below $-2,-3{ }^{\circ} \mathrm{C}$, protected of snow and a layer of mulch. It requires direct light. It does not have special demands on humidity, due to the thick hairs on the back of the leaf, and the mature plant tolerates relatively well the dry periods, as well. It requires deep, calcium-rich, light soils that are easily heated and permeable, with southwest exposure.

\section{Material and Method}

Rosmarinus officinalis plants were grown in vegetation pots, under controlled conditions of temperature, light and humidity. The nutrient substrate was composed of a mixture of perlite and peat in a ratio of 1: 3 . The plants were fed with the help of a Hoagland nutrient solution in the following groups:

Table 1. Nutritive solution Hoagland - control group (Vo)

\begin{tabular}{|c|c|c|c|c|}
\hline Components & Supply solutions & \multicolumn{4}{|c|}{ MI Supply solutions/1L } \\
\hline $2 \mathrm{M} \mathrm{KNO}_{3}$ & $202 \mathrm{~g} / \mathrm{L}$ & 2.5 & 5 & 2.5 \\
\hline $\left.2 \mathrm{M} \mathrm{Ca} \mathrm{NO}_{3}\right)_{2} \times 4 \mathrm{H}_{2} \mathrm{O}$ & $236 \mathrm{~g} / 0.5 \mathrm{~L}$ & 2.5 & 2.5 & 2.5 \\
\hline $\mathrm{Fe}$ & $15 \mathrm{~g} / \mathrm{L}$ & 1.5 & 1.5 & 1.5 \\
\hline $2 \mathrm{M} \mathrm{MgSO}_{4} \times 7 \mathrm{H}_{2} \mathrm{O}$ & $493 \mathrm{~g} / \mathrm{L}$ & 1 & 1 & 1 \\
\hline $1 \mathrm{M} \mathrm{NH} \mathrm{NO}_{3}$ & $80 \mathrm{~g} / \mathrm{L}$ & 1 & 1 & 1 \\
\hline Microelements & & & & \\
\hline $\mathrm{H}_{3} \mathrm{BO}_{3}$ & $2.86 \mathrm{~g} / \mathrm{L}$ & 0.5 & 0.5 & 0.5 \\
\hline $\mathrm{MnCl}_{2} \times \mathrm{X}_{2} \mathrm{O}$ & $1.81 \mathrm{~g} / \mathrm{L}$ & 0.5 & 0.5 & 0.5 \\
\hline $\mathrm{ZnSO}_{4} \times \mathrm{H}_{2} \mathrm{O}$ & $0.22 \mathrm{~g} / \mathrm{L}$ & 0.5 & 0.5 & 0.5 \\
\hline $\mathrm{CuSO}_{4}$ & $0.051 \mathrm{~g} / \mathrm{L}$ & 0.5 & 0.5 & 0.5 \\
\hline $\mathrm{H}_{3} \mathrm{MoO}_{4} \times \mathrm{H}_{2} \mathrm{O}$ & $0.09 \mathrm{~g} / \mathrm{L}$ & 0.5 & 0.5 & 0.5 \\
\hline $1 \mathrm{M} \mathrm{KH}_{2} \mathrm{PO}_{4}$ & $136 \mathrm{~g} / \mathrm{L}$ & 0.5 & 0.5 & 1 \\
\hline
\end{tabular}




\section{Analysis of physiological processes}

Determination of the amount of accumulated dry matter - Fragments of leaves were used as plant material, using the Kern MLS 50 thermobalance.

Determination of perspiration intensity - by the ratio obtained after the successive weighing of some organs of the plant and the relation to their fresh mass. Quantitative determination of chlorophyll pigments - using the chlorofimeter SPAD 502 Konika Minolta. Measurement of photosynthesis intensity by gas exchange method - with the help of the $\mathrm{CO}_{2}$ ANALYSIS PACKAGE, Qubit Systems (Canada), which measures the change in $\mathrm{CO}_{2}$ concentration following the photosynthesis process

\section{Analysis of volatile oils}

For the study of the composition of volatile oils of mint, rosemary and lavender, hexane was used for sample dilution (GC purity, Sigma), and for the determination of Kovats indices for volatile compounds in oils, a standard solution of linear alkanes $\mathrm{C}_{8}-\mathrm{C}_{20}$, obtained from Fluka Chemie AG, was used.

GC-MS analysis. A chromatographic gas analysis system coupled with a mass spectrometry detection system was used to analyze the volatile oils of rosemary. We used a GC Hewlett Packard HP 6890 Series coupled with a mass spectrometry Hewlett Packard 5973 Mass Selective Detector. The GC analysis conditions were:

- column: HP-5 MS, length $30 \mathrm{~m}$, inner diameter $0.25 \mathrm{~mm}$, film width $0.25 \mu \mathrm{m}$;

- temperature program: $50^{\circ} \mathrm{C}-250^{\circ} \mathrm{C}$ with a speed of $6^{\circ} \mathrm{C} / \mathrm{min}$;

- injector temperature: $280^{\circ} \mathrm{C}$;

- detector temperature: $280^{\circ} \mathrm{C}$;

- injection volume: $2 \mu \mathrm{l}$;

- carrier gas: He.

For the MS detector we worked with an EI energy of $70 \mathrm{eV}$, at a source temperature of $150^{\circ} \mathrm{C}$, scanning range 50-300 amu, scanning speed of $1 \mathrm{~s}^{-1}$ for mass spectrometry, and the obtained spectra were compared with the database NIST/EPA/NIH Mass Spectral Library 2.0 (2002). The data acquisition was done with the help of the software package Hewlett Packard Enhanced ChemStation G1701BA ver. B.01.00/1998, and the processing of gas chromatography and mass spectrometry data was performed using the program Hewlett Packard Enhanced Data Analysis from the software package above.

Table 2. Kovats retention index (KI) and retention time (RT) values for linear alkanes $\mathrm{C}_{8}-\mathrm{C}_{20}$

\begin{tabular}{clcccccc}
\hline Nr. & Linear alkane & KI & RT $($ min) & Nr. & Linear alkane & KI & RT (min) \\
\hline 1 & octane, $\mathrm{C}_{8}$ & 800 & 3.07 & 8 & pentadecane, $\mathrm{C}_{15}$ & 1500 & 17.39 \\
2 & nonane, $\mathrm{C}_{9}$ & 900 & 4.37 & 9 & hexadecane, $\mathrm{C}_{16}$ & 1600 & 19.39 \\
3 & decane, $\mathrm{C}_{10}$ & 1000 & 6.23 & 10 & heptadecane, $\mathrm{C}_{17}$ & 1700 & 21.3 \\
4 & undecane, $\mathrm{C}_{11}$ & 1100 & 8.44 & 11 & octadecane, $\mathrm{C}_{18}$ & 1800 & 23.11 \\
5 & dodecane, $\mathrm{C}_{12}$ & 1200 & 10.76 & 12 & nonadecane, $\mathrm{C}_{19}$ & 1900 & 24.83 \\
6 & tridecane, $\mathrm{C}_{13}$ & 1300 & 13.06 & 13 & eicosane, $\mathrm{C}_{20}$ & 2000 & 26.48 \\
7 & tetradecane, $\mathrm{C}_{14}$ & 1400 & 15.28 & & & & \\
\hline
\end{tabular}

Determination of Kovats retention indices (KI). The identification of the compounds following the GC-MS analysis was performed, in parallel with the identification based on the MS spectra, based on the Kovats retention indices $(\mathrm{KI})$, too, for the cases where retention index data were available for the corresponding standards. Important mono- and sesquiterpenoids could be identified in this way. In addition to the possibility of identifying compounds, for many of the components of the analyzed samples, which could be clearly identified based on the MS spectra, the corresponding Kovats indices were determined for the GC column used (HP-5 MS). The values of these indices depend only on the type of column used. The temperature program, injector and detector temperatures or carrier gas flow have no influence on this parameter.
To determine the Kovats retention indices, we proceeded as follows: a sample of $2 \mu$ of a mixture of standard solution of linear alkanes $\mathrm{C}_{8}-\mathrm{C}_{20}$ in chromatograph gas was injected into the same chromatographic column and the same conditions of analysis as in the case of basil volatile oil. After confirmation (based on MS spectra) of the linear alkane structures separated by GC analysis (Table 2), we determined the retention time (RT) for each component of the mixture.

\section{Results and Discussions}

We have first investigated the total chlorophyll content with noticeable differences between the experimental fertilization groups as follows: 


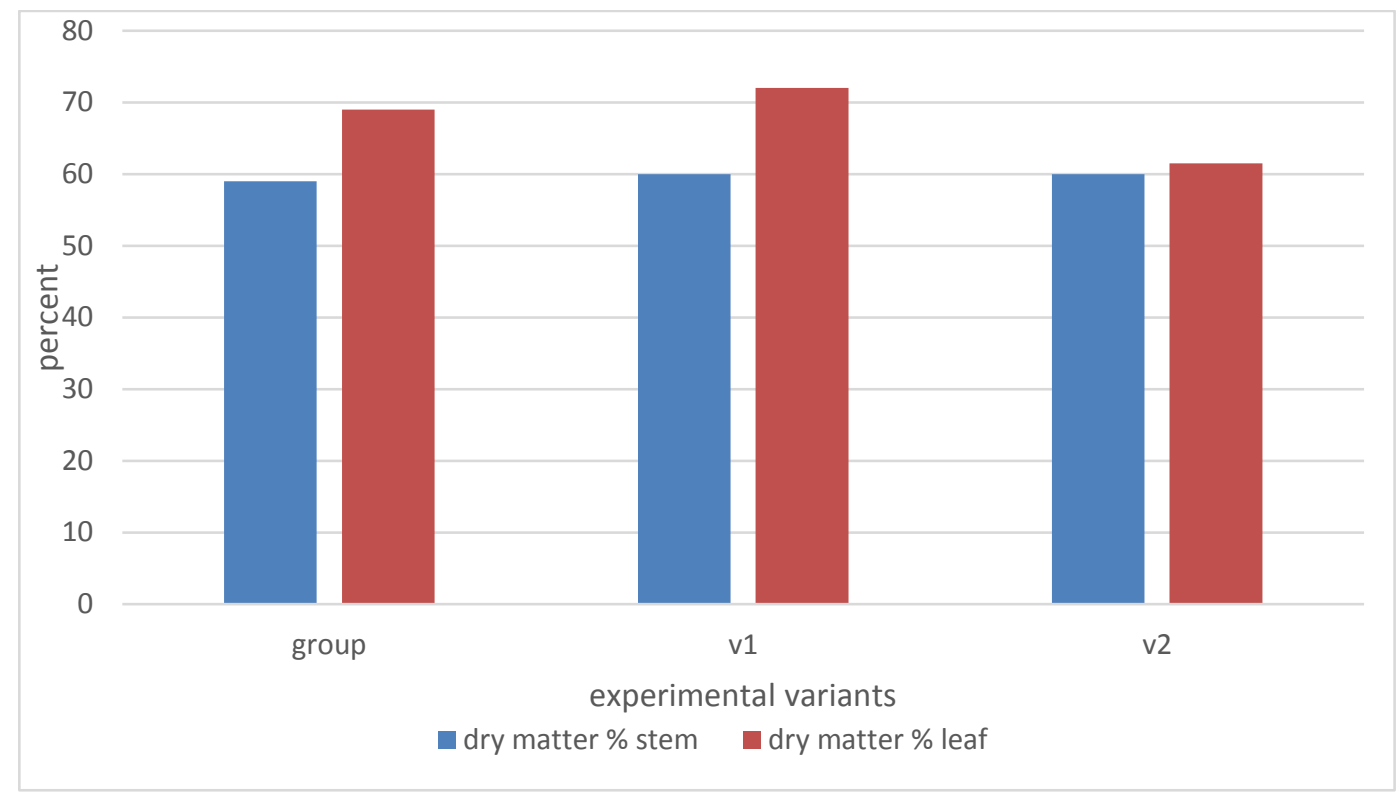

Figure 1. Dry matter content of the rosemary plants (\%).

Our results show that a high percentage of the dry matter was detected in the case of the leaf samples compared to those from the strain. It can also be observed, in the leaf fragments, that there are significant differences between the experimental groups, higher values being registered in group V1, followed by the control group and group V2.

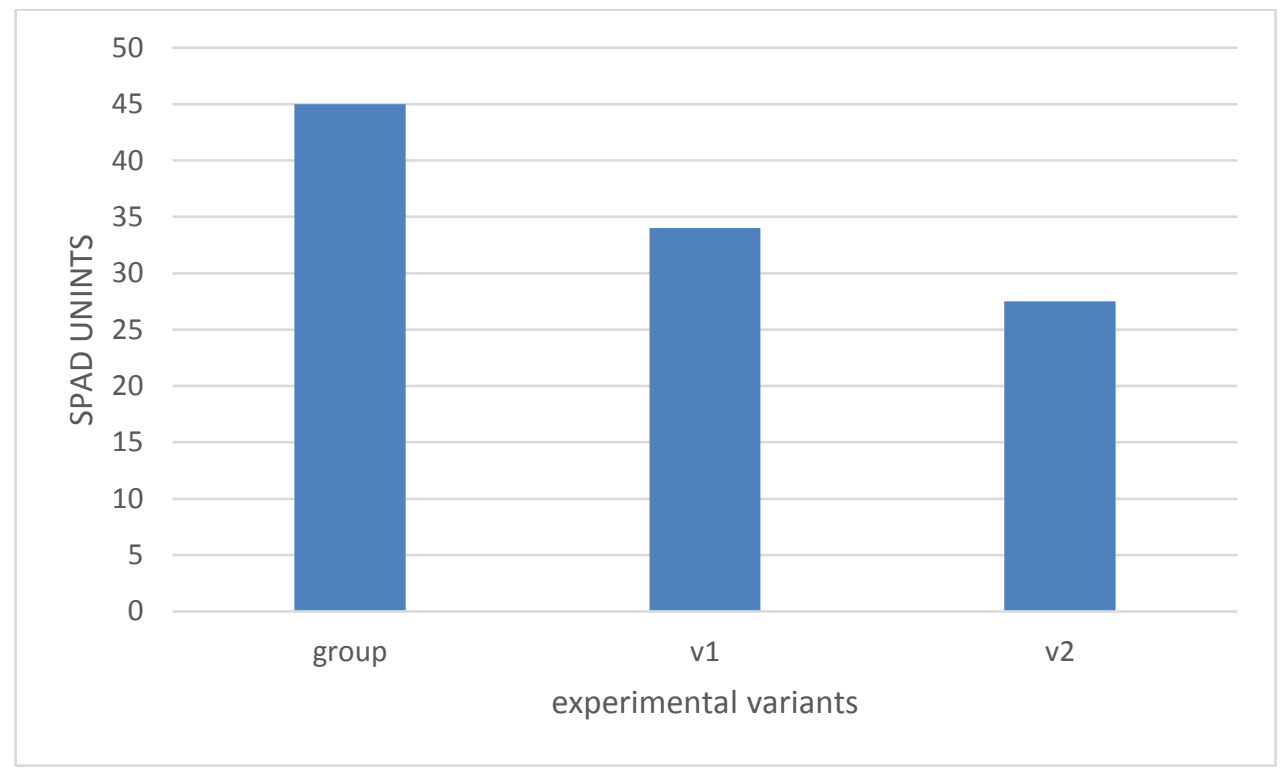

Figure 2. Determination of total chlorophyll content (SPAD).

Regarding the total chlorophyll content expressed in SPAD units, it can be seen that a higher value was found in the control group (45 SPAD), followed by group V3, while a lower value was recorded in group V2 (27.5 SPAD).

Another physiological process studied was transpiration expressed by the amount of water removed relative to the fresh mass of plant material per unit time (sweat rate). In this case it can be seen that there are differences between the studied groups, so a higher rate of perspiration was observed in the case of group V3 compared to the control group and V2, which had a lower value. 


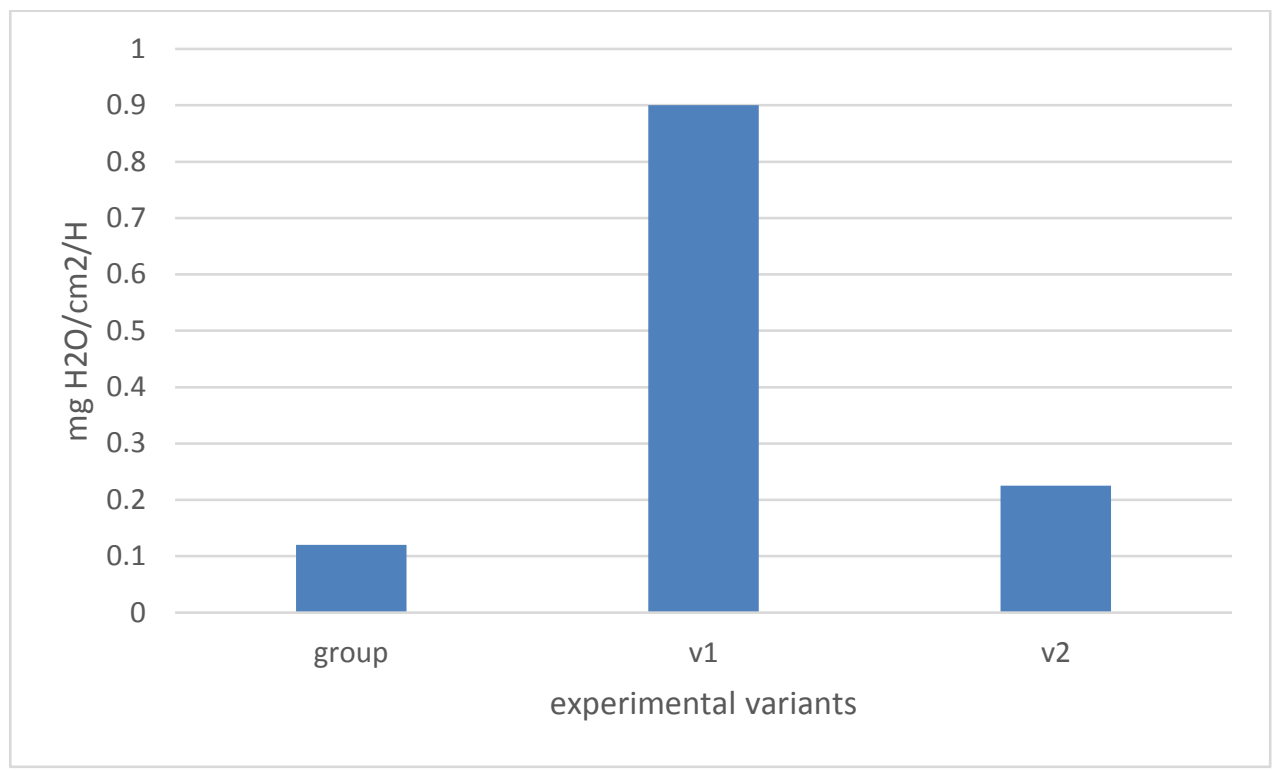

Figure 3. Intensity of transpiration in the case of the studied experimental groups.

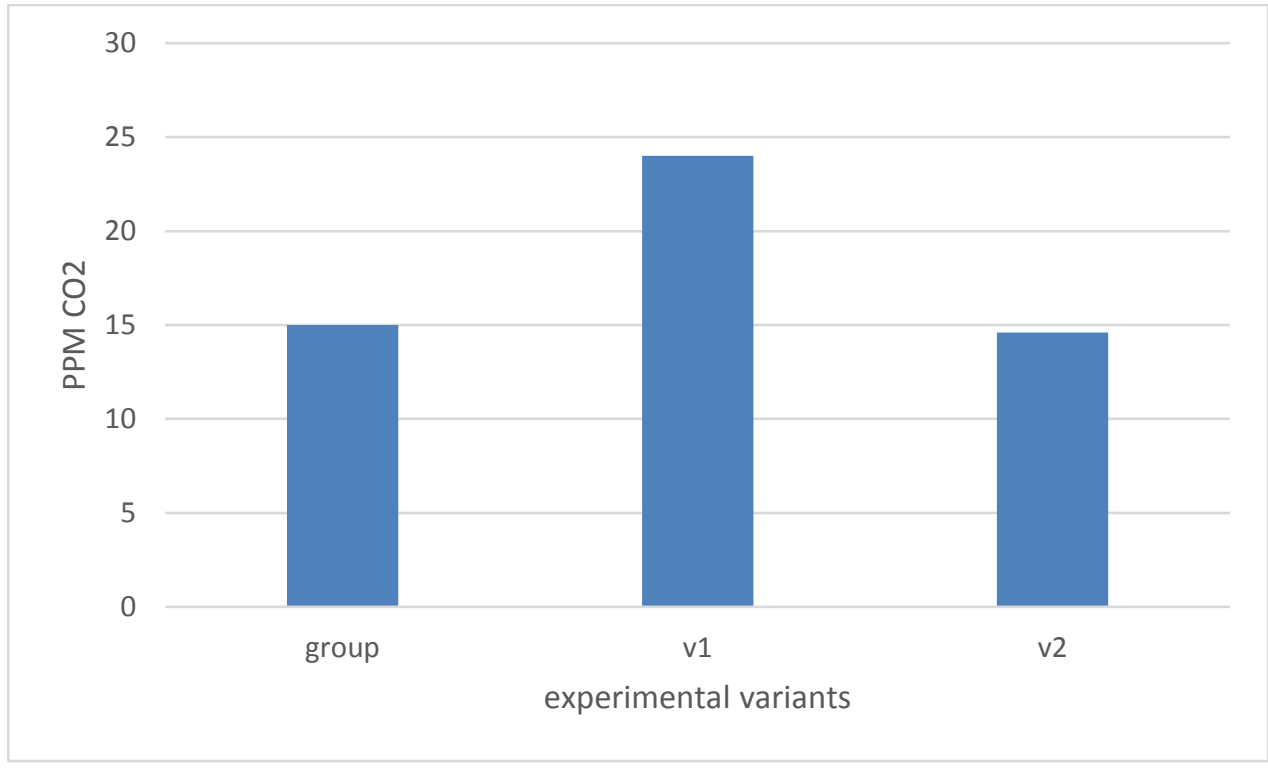

Figure 4. Results on the determining of photosynthesis intensity.

In the case of determinations made in order to establish the photosynthetic intensity by the gas exchange method $\left(\mathrm{CO}_{2}\right.$ uptake and $\mathrm{O}_{2}$ release), we observed the existence of differences between the three groups studied, so a higher intensity was recorded in the case of group V1 (added with phosphorus), followed by group V2 (added with K) and control group.

\section{Analysis of volatile rosemary oil}

The main compounds identified and quantified in rosemary volatile oil based on gas chromatographic analyzes coupled with mass spectrometry, GC-MS, were monoterpenoids and, to a lesser extent, sesquiterpenoids.
Of the monoterpenoids, the most concentrated was terpinen-4-ol $(19,2 \%), \gamma$-terpinene $(11 \%)$, and $\alpha$-terpinene $(7,8 \%)$, followed by other mono- and sesquiterpenoides in concentrations below 6\% $(\beta$-phellandrene $-3.7 \%$, limonene $-4.2 \%$, terpineol $-5.4 \%$, $\alpha$-terpineol $-4.8 \%$. The experimental mass spectra and from the NIST database are shown in the figures 6-8. This is also confirmed by the literature. PRABODH SATYAL et al, 2017[14], in a similar experiment, identified that oils were dominated by (+)- $\alpha$-pinene $(13.5 \%-37.7 \%), 1,8$-cineole $(16.1 \%-29.3 \%)$, (+)-verbenone $(0.8 \%-16.9 \%)$, (-)-borneol $(2.1 \%-6.9 \%)$, $(-)$-camphor $(0.7 \%-7.0 \%)$, and racemic limonene $(1.6 \%-4.4 \%)$. 


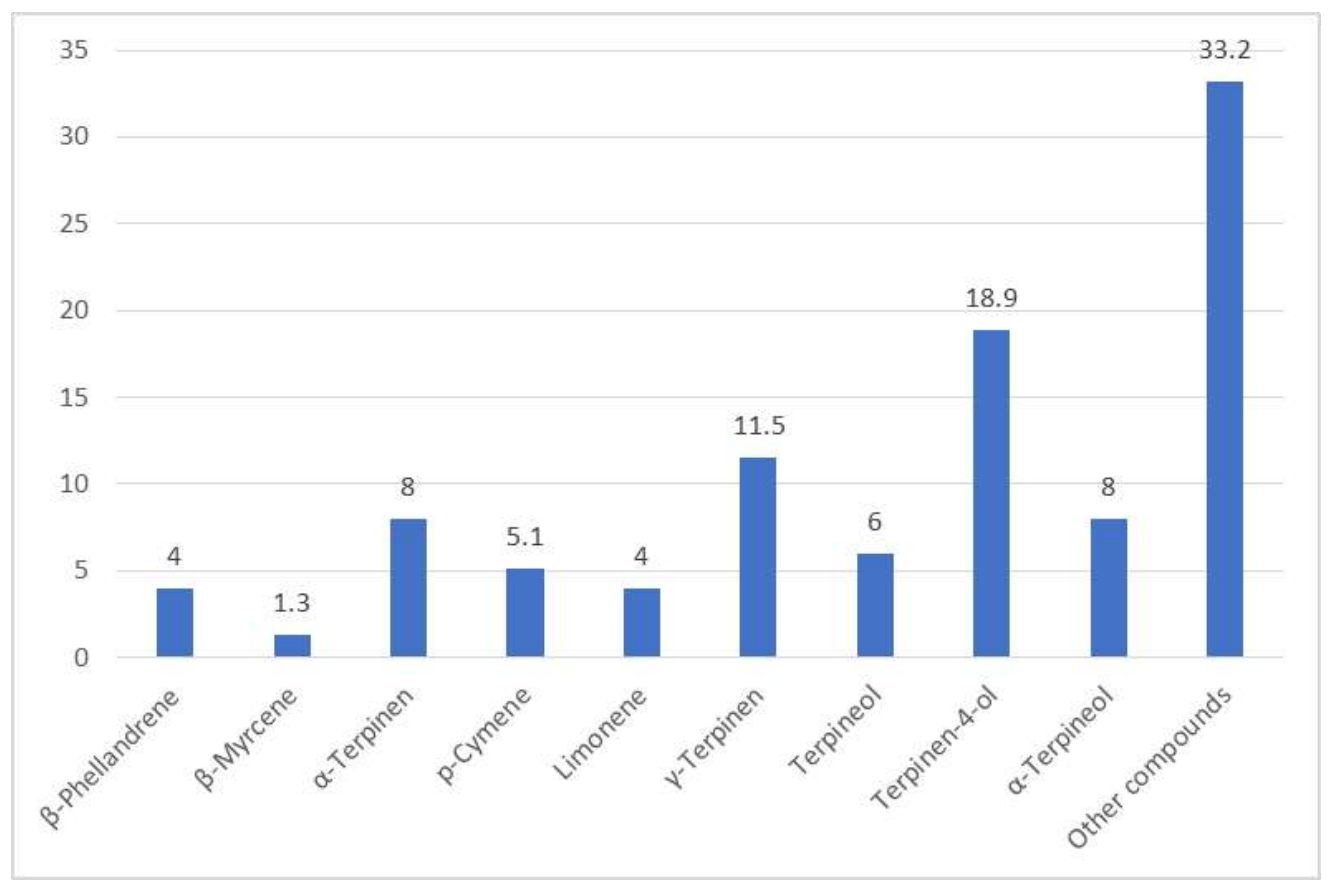

Figure 5. Results of GC-MS analyzes (identification of MS and relative percentage concentrations) for rosemary volatile oil.

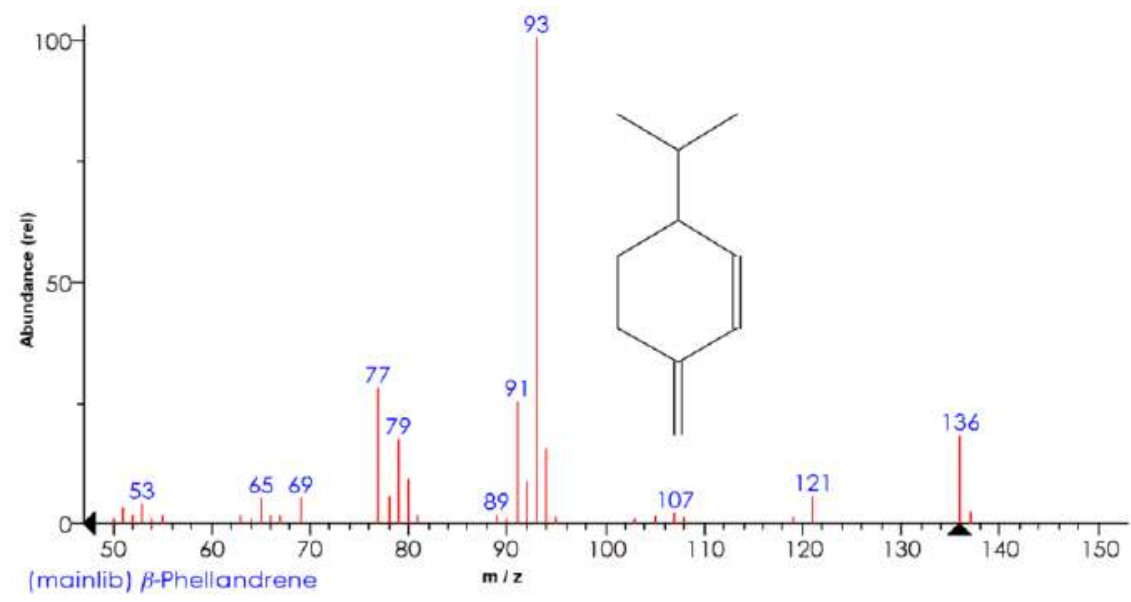

Figure 6. Mass spectra from NIST database for $\beta$-phellandren.

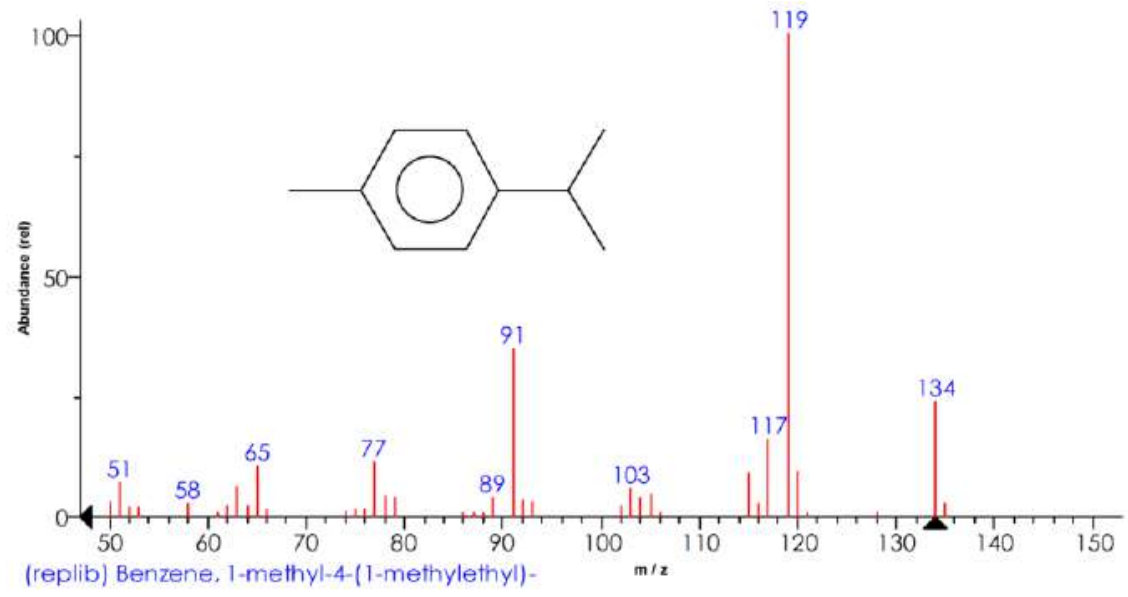

Figure 7. Mass spectra from the NIST database for $p$-cymene. 
C. BOUTEKEDJIRET et al. (2003) [15], in an experiment in which they have analyzed the volatile oils from 5 samples, from different areas of Algeria, found that the main compounds identified were pinene and camphene. Also Iram Ayoob1 et al. conclude, analyzing samples of rosemary from Kashmir province, India, which the essential oil analysis of $R$. officinalis leads to the identification of 38 constituents. Analyzing the volatile oils in the species
Humulus lupulus L., a number of 20 compounds were identified by gas chromatography, in a similar experiment aimed at the biochemical characterization of hop (LIANA SALANȚĂ et al, 2018[16]).

The essential oil was dominated by $\alpha$-pinene (16.33), 1, 8-cineole (14.33), camphor (22.01), camphene (9.28), $\beta$-pinene (5.97), $\beta$-phellandrene (5.19), bornyl acetate (4.59), myrcene (4.31) and borneol (3.35).

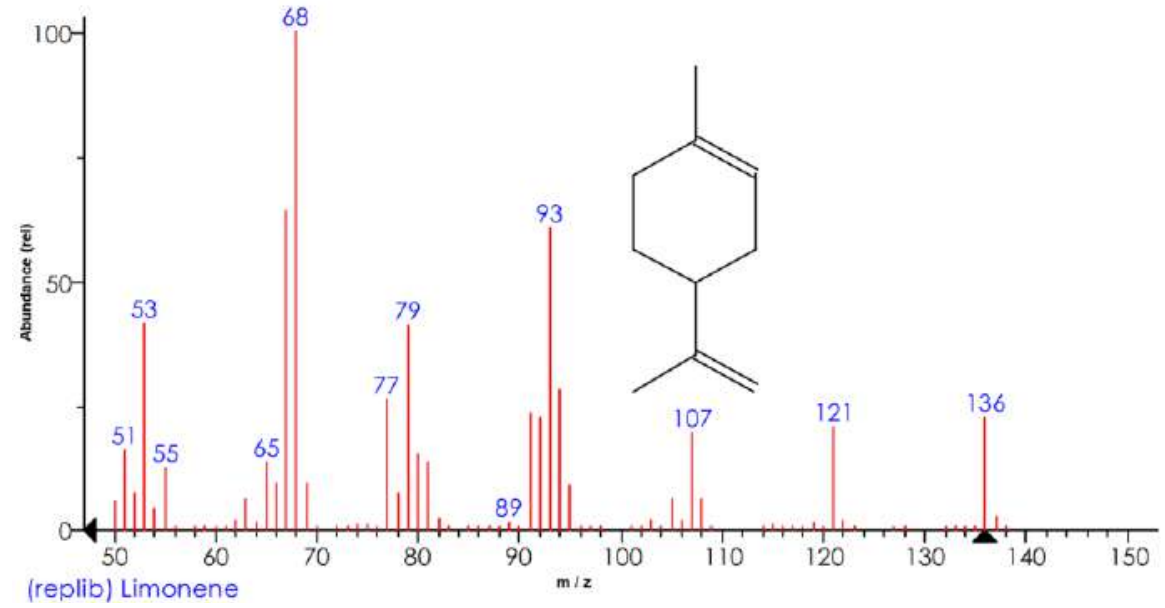

Figure 8. Mass spectra from the NIST database for limonene.

The differentiated distribution of the active principles (phenolic diterpenes, flavonoids and rosmarinic acid) during the vegetative cycle in different parts of the plant (stems, leaves, flowers) was highlighted (DEL BAÑO et al, 2003[17]). The nutritional factors have played a role in directing rosemary production and nutritional principles. MORETTI et al, 1998 [18 studied the influence of iron administered foliar to rosemary under irrigated and nonirrigated cultivation conditions and found a significant increase in the concentration of verbenone in the oil of irrigated plants. This was attributed to more intense oxidative processes under the influence of iron, which converted $\alpha$-pinene into verbenyl derivatives. Higher concentrations of verbenone in $R$. officinalis oil after ironbased treatment increase its value for the perfume industry. DEEF, 2007 [19] highlighted the influence of copper on plant growth and the content of minerals, carbohydrates and essential oils of rosemary in protected conditions. The obtained results revealed that the applied copper treatments determined a significant increase of the content of essential oils and the increase of the concentration of verbenone and 1,8-cineole in oil, at the same time with the decrease of $\alpha$-pinene content. The influence of copper on physiological parameters (growth, leaf relative water content - LRWC, cell membrane permeability) and on some processes and compounds in rosemary plants (lipid peroxidation, and total phenolic content - TPC) were studied by HEJAZI-MEHRIZI et al, 2012 [20] in a hydroponic condition.

\section{Conclusions}

From a physiological point of view, in terms of dry matter percentage, we may observe that the highest percentage was registered in the case of samples from leaves, in the experimental group V1. In the case of determination of total chlorophyll content, the highest value was found in the case of the control group. The intensity of perspiration was found to have the highest rate in the case of group V3. The intensity of photosynthesis was found to be higher in the case of group V1.

In terms of biochemical characterization, the volatile oils analyzed showed a significant number of volatile compounds (over 9 volatile compounds identified), most belonging to the class of monoterpenoids and sesquiterpenoids.

Rosemary volatile oil had a more uniform distribution of the constituent compounds, the most concentrated being the tertiary alcohol terpinen-4-ol (19,2\%) and monoterpene $\gamma$-terpinen which is most likely one of the main sources in the biosynthesis process of terpinene-4-ol. Following the studies carried out, it is recommended the differentiated application of fertilizers with phosphorus and potassium in 
order to make a superior use of rosemary essential oil on the market of profile products.

\section{References}

1. AL-SEREITIA M.R., ABU-AMERB K.M., SENA P. Pharmacology of rosemary (Rosmarinus officinalis Linn.) and its therapeutic potentials. Indian Journal of Experimental Biology, 37, pp. 124-131 (1999).

2. KOSAKA K., YOKOI T. Carnosic Acid, a Component of Rosemary (Rosmarinus officinalis L.), Promotes Synthesis of Nerve Growth Factor in T98G Human Glioblastoma Cells. Biological and Pharmaceutical Bulletin, 26(11), pp. 1620-1622 (2003).

3. PETERSEN M., SIMMONDS M.S. Rosmarinic acid. Phytochemistry, 62(2), pp. 121-125 (2003).

4. BOZIN B., MIMICA-DUKIC N., SAMOJLIK I., JOVIN E. Antimicrobial and antioxidant properties of Rosemary and Sage (Rosmarinus officinalis L. and Salvia Officinalis L., Laminaceae) essential oils. Journal of Agricultural and Food Chemistry, 55, pp. 7879-7885 (2007).

5. BOTSOGLOU N.A., GOVARIS A., GIANNENAS I., BOTSOGLOU E., PAPAGEORGIOU G. The incorporation of dehydrated rosemary leaves in the rations of turkeys and their impact on the oxidative stability of the produced raw and cooked meat. International Journal of Food Science and Nutrition, 58(4), pp. 312320 (2007).

6. MONINO M.I., MARTÍNEZ C., SOTOMAYOR J.A., LAFUENTE A., JORDÁN M.J. Polyphenolic transmission to segureño lamb meat from ewes dietary supplemented with the distillate from rosemary (Rosmarinus officinalis) leaves. Journal of Agricultural and Food Chemistry, 56, pp. 3363-3367 (2008).

7. NIETO G., DIAZ P., BAÑÓN S., GARRIDO M.D. Dietary administration of ewe diets with a distillate from rosemary leaves (Rosmarinus officinalis L.): Influence on lamb meat quality. Meat Science, 84(1), pp. 23-29 (2010).

8. WELLWOOD C.R.L., COLE R.A. Relevance of carnosic acid concentrations to the selection of rosemary, Rosmarinus officinalis (L.), accessions for optimization of antioxidant yield. J. Agricultural Food Chemistry, 52(20), pp. 6101-6107 (2004).

9. NABAVI S.F., TENORE G.C., DAGLIA M., TUNDIS R., LOIZZO M.R., NABAVI S.M. The cellular protective effects of rosmarinic acid: from bench to bedside. Curr Neurovasc Res, 12(1), pp. 98-105 (2015).

10. PETERSEN M., ABDULLAH Y., BENNER J., EBERLE D., GEHLEN K., HÜCHERIG S., JANIAK V., KIM K.H., SANDER M., WEITZEL C., WOLTERS S. Evolution of rosmarinic acid biosynthesis. Phytochemistry, 70(15-16), pp. 1663-79 (2009).
11. PEÑUELAS J., LLUSiÀ J. Effects of Carbon Dioxide, Water Supply, and Seasonality on Terpene Content and Emission by Rosmarinus officinalis. Journal of Chemical Ecology, 23(4), pp. 979-993 (1997)

12. LUIS J.C., JOHNSON C.B. Seasonal variations of rosmarinic and carnosic acids in rosemary extracts. Analysis of their in vitro antiradical activity. Spanish Journal of Agricultural Research, 3(1), 106-112 (2005).

13. HIDALGO P.J., UBERA J.L., TENA M.T., VALCÁRCEL M. Determination of the Carnosic Acid Content in Wild and Cultivated Rosmarinus officinalis. Journal of Agricultural Food Chemistry, 46 (7), pp. 2624-2627 (1998).

14. PRABODH SATYAL PRABODH SATYAL, TYLER H. JONES, ELIZABETH M. LOPEZ, ROBERT L. MCFEETERS, NASSER A. AWADH ALI, IMAN MANSI, ALI G. AL-KAF, WILLIAM N. SETZER. CHEMOTYPIC Characterization and Biological Activity of Rosmarinus officinalis. MDPI-Foods, 6(20) (2017).

15. C. BOUTEKEDJIRET, F. BENTAHAR, R. BELLABBES, J.M. BESSIERE. Extraction of rosemary essential oil by steam distillation and hydrodistillation. Flavour and Fragrance Journal (2003).

16. LIANA C. SALANŢĂ, SONIA A. SOCACI, MARIA TOFANĂ, ELENA MUDURA, CARMEN R. POP, MELINDA NAGY, ANTONIA ODAGIU. Characterization of volatile components in hop pellets using intube extraction GC-MS analysis. Rom Biotechnol Lett, 23(2), 2018.

17. DEL BAÑO M.J., LORENTE J., CASTILlO J., BENAVENTE-GARCIA O., DEL RIO J.A., ORTUÑO A., QUIRIIN K.-W., GERALD D. Phenolic Diterpenes, Flavones, and Rosmarinic Acid Distribution during the Development of Leaves, Flowers, Stems, and Roots of Rosmarinus officinalis. Antioxidant Activity. J. Agric. Food Chem., 51(15), pp. 4247-4253 (2003).

18. MORETTI M.D.L., PEANA A.T., PASSINO G.S., BAZZONI A., SOLINAS V. Effects of iron on yield and composition of Rosmarinus officinalis L. essential oil. Journal of Essential Oil Research, 10(1), pp. 43-49 (1998).

19. DEEF H.A.-S. Cupper treatments and their effects on growth, carbohydrates, minerals and essential oils content of Rosmarinus officinalis L. World Journal of Agricultural Sciences, 3(3), pp. 322-328 (2007).

20. HEJAZI-MEHRIZI M., SHARIATMADARI H., KHOSHGOFTARMANESH A.H., DEHGHANI F. Copper effects on growth, lipid peroxidation, and total phenolic content of rosemary leaves under salinity stress. Journal of Agricultural Science and Technology, 14(1), pp. 205-212 (2012). 